\title{
MỘT SỐ PHƯƠNG PHÁP RÈN KỸ NĂNG TẬP ĐỌC NHẠC CHO HỌC SINH KHỐI TRUNG HỌC CƠ SỞ TRUỜNG PHỔ THÔNG TUYÊN QUANG
}

\author{
Hà Thị Thúy Linh ${ }^{a^{*}}$ \\ ${ }^{a}$ Truoòng Đại học Tân Trào \\ *Email: linhha.cdtq@gmail.com
}

\section{Thông tin bài viết}

Ngày nhận bài:

24/3/2020

Ngày duyệt đăng:

$10 / 6 / 2020$

\section{Tù khóa:}

Tạp đọc nhac; Hoc sinh Trung hoc co sớ; Giáo viên; phuoong pháp dạy hoc; ky năng tập đọc nhạc.

\section{Tóm tắt}

Để đạt được mục tiêu và nhiệm vụ của môn Âm nhạc ở trường Trung học cơ sở (THCS) cần tạo nên một "Trình độ văn hoá Âm nhạc nhất định", bao gồm sự hiểu biết, năng lực thực hành tối thiểu và năng lực cảm thụ âm nhạc cho học sinh. Để đạt được điều đó, đòi hỏi người giáo viên đứng lớp phải có sự đầu tư thời gian để tìm tòi, nghiên cứu nhằm tìm ra phương pháp tối ưu trong quá trình tổ chức hoạt động học tập cho các em.

Hiện nay, hầu hết học sinh khối THCS trường Phổ thông Tuyên Quang (TSE) học phân môn Tập đọc nhạc (TĐN) chưa tốt, hạn chế về kỹ năng TĐN cơ bản. Bài viết này đưa ra một số phương pháp rèn kỹ năng TĐN cho học sinh, bao gồm các kỹ năng: đọc cao độ, thể hiện trường độ và tiết tấu; gõ phách; đọc có sắc thái... nhằm giúp học sinh khối THCS trường Phổ thông Tuyên Quang học phân môn TĐN hiệu quả hơn.

\section{Mở đầu}

Tập đọc nhạc (TĐN) là một thuật ngữ của chương trình âm nhạc ở trường phổ thông. Phân môn TĐN ở trường THCS có nội hàm như môn Xướng âm ở các trường âm nhạc chuyên nghiệp, nhưng dạy TĐN cho học sinh THCS nội dung và yêu cầu rất khiêm tốn. Do thời lượng hạn hẹp, mà việc dạy âm nhạc ở đây lại đại trà cho mọi đối tượng học sinh, vì thế nếu yêu cầu và thiết kế nội dung như học Xướng âm ở các trường âm nhạc chuyên nghiệp sẽ không có điều kiện thực thi, và kết quả học tập của học sinh sẽ rất hạn chế. Mặt khác, mục tiêu giáo dục âm nhạc ở THCS nhằm xây dựng một trình độ văn hóa âm nhạc nhất định, không đi sâu vào những kĩ năng, kĩ xảo của việc đào tạo người làm nghề âm nhạc nên phân môn TĐN chỉ dạy cho học sinh những kiến thức ở mức độ đơn giản, phổ thông nhất. $[6 ; 78]$

Với phương châm "Học vui - Vui học", chương trình Âm nhạc ở trường THCS có nhiều nội dung đa dạng, phong phú với các phân môn như: Học hát, Nhạc lí -TĐN và Âm nhạc thường thức, qua đó mang lại cho các em nhiều niềm vui và sự hứng thú đối với môn học. Riêng đối với phân môn $\mathrm{TĐN}$, giáo viên cần cho học sinh biết rằng: tập đọc nhạc không phải như tập đọc chữ, tập đọc nhạc sẽ không thể đọc như nói mà phải đọc như hát. Tập đọc nhạc chính là cho các em làm quen với chữ "nhạc". Dạy TĐN ở trường THCS chỉ nhằm bước đầu tập luyện giải mã các kí hiệu ghi chép nhạc và rèn cho các em có ý thức hát đúng cao độ, trường độ, nhịp điệu, làm quen với các loại hình tiết tấu... để giúp HS hát chính xác hơn về cao độ, lời ca, nhịp, phách của bài hát. Qua những bài $\mathrm{TĐN}$ đồng thời cũng rèn cho các em nhạc cảm tốt hơn và giúp các em phát huy khả năng sáng tạo Âm nhạc của mình.

Trên cơ sở chỉ mang tính thực nghiệm, tôi xin trình bày một số phương pháp mà tôi đã vận dụng có hiệu quả trong hoạt động giảng dạy phân môn TĐN. Hy 
vọng rằng đây sẽ là những ý kiến bổ ích để cho các đồng nghiệp có thể tham khảo trong hoạt động giảng dạy của mình.

\section{Nội dung nghiên cứu}

\subsection{Khái quát về lịch sử vấn đề nghiên cứu}

Qua quá trình nghiên cứu và tìm hiều chúng tôi thấy, đã có một số tài liệu có liên quan đến lĩnh vực nghiên cứu của bài báo như:

Hoàng Long, Hoàng Lân (2010), Phưong pháp dạy học âm nhạc, Nxb Đại học Sư phạm. Cuốn sách đưa ra hệ thống các phương pháp dạy học âm nhạc ở trường Trung học sơ sở như: Phương pháp dạy hát, phương pháp dạy tập đọc nhạc, phương pháp dạy nghe nhạc, phương pháp dạy Âm nhạc thường thức, phương pháp tổ chức hoạt động âm nhạc ngoại khóa.

Trịnh Hoài Thu (2011), Phurong pháp dạy hoc Ký xướng âm trong đào tạo giáo viên Âm nhạc phổ thông, $\mathrm{Nxb}$ Âm nhạc, Hà Nội. Cuốn sách đi sâu vào các phương pháp rèn luyện kỹ năng xướng âm, ghi âm.

Ngoài hai tài liệu trên còn có một số luận văn thạc sỹ, có liên quan đến bài viết như:

Luận văn tốt nghiệp cao học chuyên nghành Lý luận và phương pháp dạy học âm nhạc của Nguyễn Văn Dương với đề tài "Nâng cao chất lượng giảng dạy môn Đọc - ghi nhạc cho sinh viên Cao đẳng Su phạm Âm nhac trường Cao đẳng Su phạm Trung Uơng”. Đề tài khảo sát thực trạng tình hình dạy học môn Đọc - ghi nhạc của sinh viên tại trường Cao đẳng Sư phạm Trung Ương, và đưa ra những giải pháp nâng cao chất lượng dạy và học phân môn này.

Có thể nói, các đề tài nêu trên đều rất quan tâm đến việc đưa ra những giải pháp cải tiến phương pháp dạy học môn Tập đọc nhạc (xướng âm). Tuy nhiên, chưa có công trình nào nghiên cứu về phương pháp rèn kỹ năng Tập đọc nhạc cho học sinh khối THCS trường Phổ thông Tuyên Quang.

\subsection{Một số phương pháp rèn kỹ năng Tập đọc} nhạc cho học sinh THCS

Để giờ học TĐN có hiệu quả như mong muốn, tôi đã lựa chọn một số phương pháp phù hợp với phân môn, phù hợp với khả năng của bản thân và điều kiện về cơ sở vật chất của nhà trường. Sau nữa là sự phối hợp một cách hợp lý các phương pháp đó trong từng tiết dạy, để phù hợp với trình độ tiếp thu của từng đối tượng học sinh.
Phương pháp đặt câu hỏi thường sử dụng khi bắt đầu học bài $\mathrm{TĐN}$, giáo viên có thể đặt các câu hỏi liên quan đến bài TĐN của tiết học đó để học sinh tìm hiểu bài TĐN. Giáo viên nên đưa ra một số câu hỏi phù hợp, nhằm củng cố lại cho các em kiến thức về nhạc lý cơ bản, giúp các em vừa đọc tốt bài $\mathrm{TĐN}$, vừa có cơ sở để ghi nhớ các kí hiệu âm nhạc, vừa tăng thêm khả năng vận dụng những kiến thức lý thuyết vào đọc nhạc ở những tiết học sau, ví dụ:

- Bài TĐN này viết ở nhịp mấy? Ô nhịp đầu tiên là ô nhịp gì?

- Em hãy nhận xét về cao độ, trường độ, các kí hiệu âm nhạc đã học có trong bài?

Qua phương pháp đặt câu hỏi như trên, bước đầu giáo viên đã giúp học sinh nhớ lại kiến thức nhạc lý và cách thực hiện các kí hiệu khi đọc bài TĐN. Đồng thời tạo cho học tính tích cực, chủ động trong giờ học.

\subsubsection{Phương pháp rèn kỹ năng đọc cao độ}

\subsubsection{1. Đoc gam}

Đọc gam là bước đầu tiên của việc rèn luyện đọc cao độ.

- Thứ nhất: Lấy cao độ cho âm chủ

Thực tế, giọng người không thể đáp ứng được cao độ tuyệt đối trên đàn cho âm chủ của một giọng nào đó. Hơn nữa ở lứa tuổi của học sinh THCS, về mặt sinh lí các em đang vỡ giọng và rất hạn chế khi hát các nốt cao hoặc nốt quá thấp. Vì vậy, khi lấy cao độ cho âm chủ giáo viên có thể dịch giọng lên hoặc xuống sao cho phù hợp với khả năng tầm cữ giọng của học sinh.

Ví dụ: Khi cho học sinh đọc gan F-dur

1)

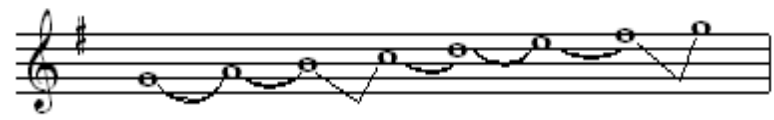

Nếu lấy cao độ tuyệt đối trên đàn, học sinh sẽ không đọc được các nốt e2, f2, g2 (Mi, Fa, Sol ở quãng tám thứ 2) vì ba nốt này cao quá sức các em có thể hát được. Do vậy, giáo viên có thể dịch xuống một quãng $2 \mathrm{~T}$ hoặc $3 t$ rồi cho học sinh đọc gam.

Cần lưu ý, Sau khi đọc gam nên tránh dịch giọng lên hoặc xuống bởi người đọc rất dễ bị mất cảm giác về âm của điệu thức, nhất là khi mới đọc sang một giọng mới. Giáo viên nên chọn tầm cữ giọng vừa phải khi đọc gam để khi đọc vào bài TĐN cụ thể học sinh không phải thay đổi độ cao của âm chủ đã chọn.

\subsubsection{Phương pháp đặt câu hỏi}


- Thứ 2: Đọc gam

Đọc chậm theo bước lần từ bậc I ở quãng tám thứ nhất đến bậc I ở quãng tám thứ hai và đọc đi xuống. Dù là giọng trưởng hay giọng thứ thì đều đọc gam từ dưới đi lên sau đó đọc đi xuống. Giáo viên cần hướng dẫn cho học sinh khi đọc từng bậc phải ghi nhớ trong đầu khoảng cách của các quãng 2 từ bậc nọ sang bậc kia.

Ví dụ: Gam G-dur

2)

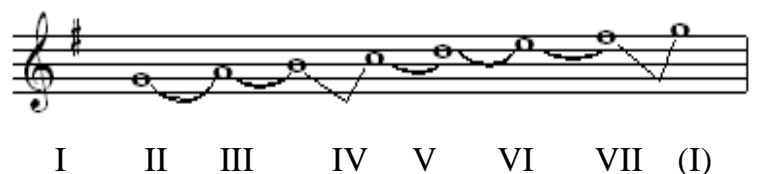

Khi đọc gam giáo viên đàn cao độ từng bậc cho học sinh đọc theo, đọc đi lên và đi xuống thuần thục. Ở những tiết học sau, nếu vẫn là giọng cũ thì giáo viên chỉ lấy cao độ âm chủ và để học sinh tự đọc gam. Điều đó sẽ phát huy được tính tự chủ của người học.

Đối với bài TĐN có những nốt vượt qua một quãng tám thì khi luyện đọc gam giáo viên nên cho học sinh đọc gam mở rộng trên một quãng tám để ứng dụng vào bài học thuận lợi hơn.

Ví dụ: Khi đọc bài TĐN ở giọng G-dur mà cao độ có nốt Rê quãng tám thứ nhất thì giáo viên có thể cho học sinh đọc gam như sau:

3)

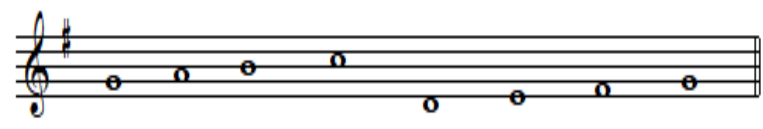

4)

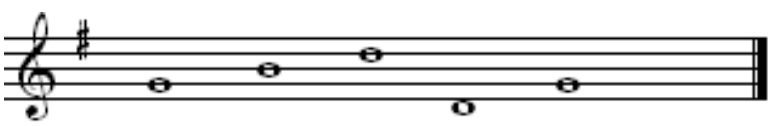

Khi đọc gam thứ hòa thanh và thứ giai điệu cần chú ý so sánh sự khác nhau giữa chúng với gam thứ tự nhiên.

\subsubsection{Luyện đọc quãng}

- Luyện đọc các quãng mô tiến Diatonic:

+ Mô tiến quãng 2:

Ví dụ:

5) C-dur:

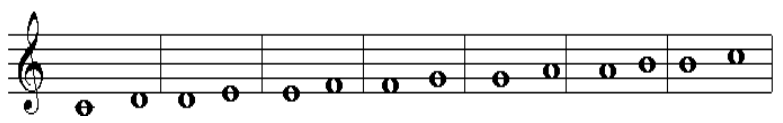

+ Mô tiến quãng 3:

Ví dụ:

6) C-dur:

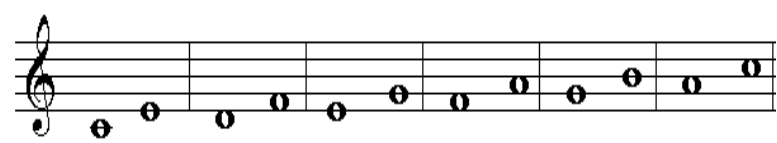

- Luyện đọc các quãng không cùng loại

+ Đầu tiên có thể luyện theo bước lần của gam, giữ nguyên âm chủ

Ví dụ: giọng C-dur

7)

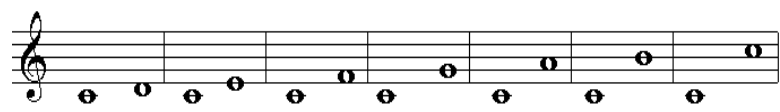

8)

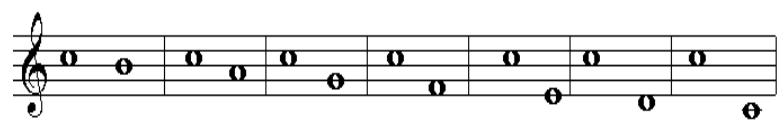

+ Sau đó giáo viên có thể cho học sinh đọc các quãng khác nhau trong gam và các quãng có trong bài TĐN mới mà học sinh chuẩn bị đọc.

\subsubsection{Luyện đọc hợp âm rải của giọng}

Đọc hợp âm rải được tiến hành với 3 hợp âm chính của giọng là hợp âm bậc $I(T, t)$, hợp âm bậc $I V(S, s)$ và hợp âm bậc $\mathrm{V}$ (D hoặc D7 của giọng trưởng tự nhiên và giọng thứ hòa thanh).

Luyện đọc hợp âm rải thường tiến hành sau khi đọc gam và đọc quãng, trước khi vào đọc bài $\mathrm{T} Đ \mathrm{~N}$, đọc từ dưới đi lên rồi đi xuống.

- Đọc hợp âm rải bậc I trước:

Ví dụ:

9)

C-dur

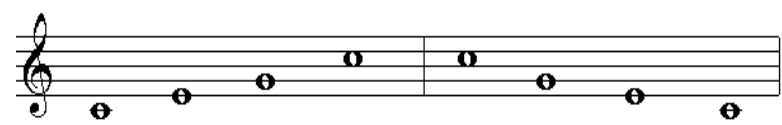

10)

a-moll

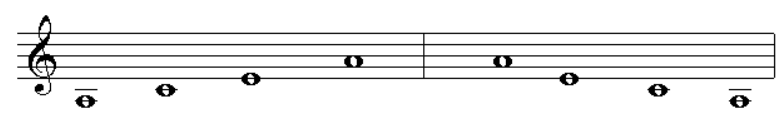

- Đọc hợp âm bậc IV

Ví dụ:

11)

C-dur

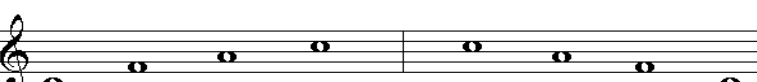


- Đọc hợp âm bậc V7

Ví dụ:

12)

C-dur

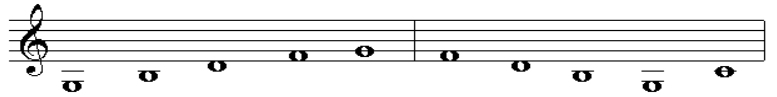

2.2.3. Phương pháp rèn luyện kỹ năng đọc trương dô

Kỹ năng đọc trường độ cần tập trung vào luyện đập phách (gõ phách) và luyện đọc tiết tấu.

* Rèn kỹ năng đập phách (gõ phách)

Phách chính là sự thể hiện độ dài của các âm thanh, là đơn vị đo thời gian trong âm nhạc. Giáo viên cần hướng dẫn cho học sinh hiểu là một phách luôn gồm hai nửa bằng nhau. Nửa đầu ứng với thời gian tay ta đập xuống một điểm nhất định, còn nửa sau tương ứng với tay ta nhấc lên ở vị trí xuất phát. [9;34]

Nếu ta qui định một phách có trường độ bằng một nốt đen thì sẽ gõ phách như sau:

Ví dụ:

13)

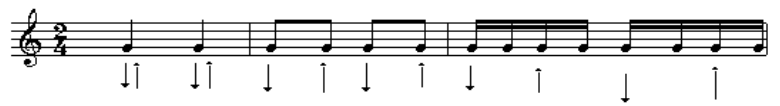

Đập phách đều đặn là cách luyện tập rất tốt cho cảm giác về độ dài của âm thanh, và giúp cho học sinh giữ nhịp tốt. Giáo viên hướng dẫn học sinh đập phách với các loại trường độ khác nhau, có thể lấy luôn các trường độ trong bài TĐN để luyện đập phách, gõ phách.

Ví dụ: TĐN số 1, sách Âm nhạc 7

14)

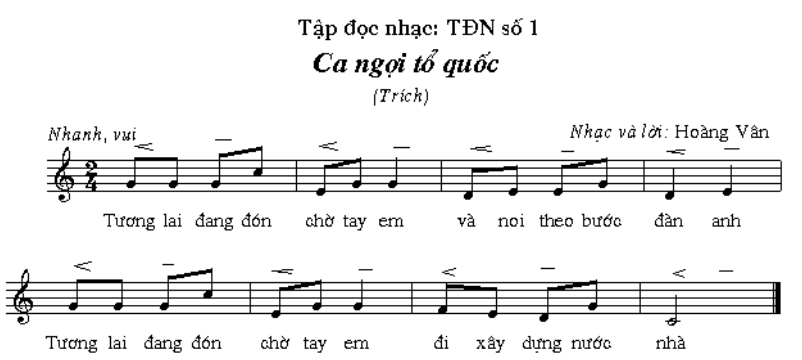

Kí hiệu $=$ là phách mạnh, — là phách nhẹ. Giáo viên có thể hướng dẫn học sinh vỗ tay đệm theo phách như sau: phách mạnh ( $=$ ) vỗ 2 lòng bàn tay vào nhau, phách nhẹ (-) vỗ lòng bàn tay phải vào cổ tay trái. Nếu dùng trống nhỏ để gõ đệm thì phách mạnh (
=- ) gõ vào mặt trống, phách nhẹ (-) gõ vào tang trống...

* Rèn luyện kỹ năng đọc tiết tấu.

Tiết tấu chỉ sự liên tục có tổ chức độ dài ngắn của âm thanh. Nói cách khác, tiết tấu là sự tương quan về trường độ của các âm thanh nối tiếp nhau. Tiết tấu là một trong những yếu tố có tính tạo hình của tác phẩm. [9;36]

Để rèn kỹ năng đọc tiết tấu cần thực hiện như sau:

Giáo viên có thể lấy âm hình tiết tấu chủ đạo của bài TĐN cho học sinh luyện đọc

- Đọc tiết tấu bằng hình nốt: Giáo viên ghi âm hình tiết tấu chủ đạo của bài TĐN lên bảng (hoặc treo bảng phụ), dùng thước chỉ vào từng nốt bằng cách đập phách, đồng thời đọc tiết tấu bằng hình nốt. Cách đọc như vậy giúp học sinh đồng thời rèn luyện cả kỹ năng đọc tiết tấu và gõ phách.

Ví dụ:

15)

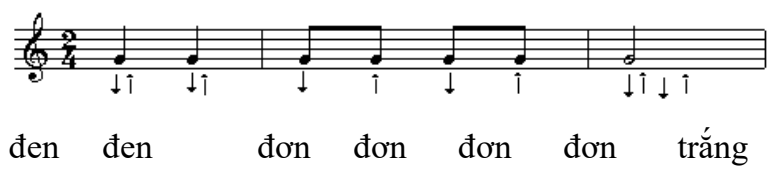

- Đọc tiết tấu bằng số: Vẫn sử dụng phương pháp gõ phách trên nhưng đọc tiết tấu thì thay hình nốt bằng số.

Ví dụ:

15)

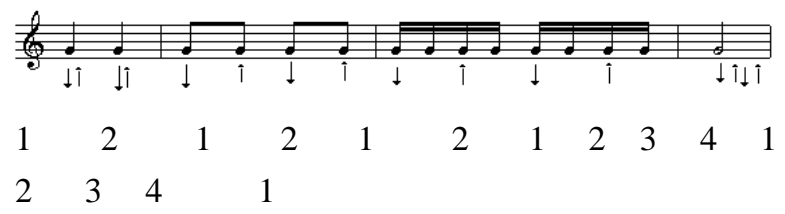

Với cách đọc tiết tấu bằng số bắt buộc học sinh phải tư duy nhiều hơn, chữ số lúc này thay cho hình nốt và nó cũng thể hiện độ dài ngắn của âm thanh, đồng thời số còn diễn tả sự phân chia nhóm trường độ của mỗi phách.

\subsubsection{Phuơng pháp rèn kỹ năng T円N ghép lòi}

TĐN ghép lời ca là cách đọc một bản nhạc có lời ca, đây chính là đọc một tác phẩm viết cho thanh nhạc. Tuy nhiên, những bài TĐN trong chương trình âm nhạc THCS chỉ là những trích đoạn của một số ca khúc. Bước ghép lời ca thực hiện sau khi học sinh đã đọc chính xác bản nhạc, có thể tiến hành theo một số cách sau: 
- Chia nhóm: một nhóm đọc nhạc và một nhóm ghép lời ca.Thực hiện như sau:

Nhóm 1 đọc nhạc câu 1 sau đó nhóm 2 ghép lời ca câu 1

Nhóm 1 đọc nhạc câu 2 sau đó nhóm 2 ghép lời ca câu 2

Đổi ngược lại, nhóm 2 đọc nhạc, nhóm 1 hát lời ca.

- Giáo viên đọc nhạc và học sinh ghép lời ca từng câu của bài TĐN. Sau đó học sinh hát hoàn chỉnh cả bài.

- Giáo viên đàn giai điệu từng câu của bài TĐN cho học sinh nghe để học sinh tự ghép lời ca.

\subsubsection{Phưong pháp luyện tập toàn bài}

Sau khi học sinh cơ bản đã đọc nhạc và ghép lời ca toàn bài thì giáo viên cho học sinh ghép toàn bài với nhạc đệm của đàn.

Đọc nhạc và hát lời ca toàn bài kết hợp gõ phách.

Chia dãy $\mathrm{A}$ đọc nhạc và gõ phách, dãy $\mathrm{B}$ hát lời ca gõ phách và đổi ngược lại.

Ôn luyện đọc nhạc và hát lời ca toàn bài theo tổ, nhóm, cá nhân.

\subsubsection{Hướng dẫn bài về nhà}

Muốn học sinh đọc tốt bài TĐN thì việc các em tìm hiểu bài trước khi đến lớp và ôn bài sau khi học xong là rất quan trọng. Để cho các em thực hiện có hiệu quả với nhiệm vụ này, giáo viên cần phải có một phương pháp hướng dẫn học sinh ôn bài về nhà phù hợp.

- Hướng dẫn sau khi học xong bài trên lớp:

+ Về nhà đọc lại bài TĐN kết hợp gõ phách thuần thục.

+ Thể hiện đúng cao độ, trường độ, tiết tấu và các kí hiệu...có trong bài

- Hướng dẫn chuẩn bị bài mới:

+ Yêu cầu học sinh chép bài TĐN vào vở chép nhạc

+ Yêu cầu học sinh nhận biết tên nốt nhạc

+ Yêu cầu học sinh nhận xét bài TĐN (nhịp, cao độ, trường độ, âm hình tiết tấu, các kí hiệu âm nhạc đã học...)

\section{Kết luận}

Qua thực tế giảng dạy cùng với những kiến thức đã học và những ý kiến đóng góp của bạn bè đồng nghiệp, bản thân tôi đã rất cố gắng để tìm ra những phương pháp tối ưu khi giảng dạy. Từ đó mà tôi đã rút ra được một số kinh nghiệm trong phương pháp dạy học, đã vận dụng vào giảng dạy và đạt hiệu quả.

Giáo viên cần lưu ý nếu áp dụng các phương pháp nêu trên phải biết chọn lọc vào từng bài TĐN sao cho hiệu quả, không thể sử dụng tất cả các phương pháp nêu trên cho dạy học một bài TĐN mà sẽ sử dụng dần dần qua từng bài học, vì thời gian cho dạy học bài $\mathrm{TĐN}$ không bao gồm cả tiết học mà còn các nội dung dạy học khác (ôn tập bài hát, âm nhạc thường thức...)

Đối với trường Phổ thông Tuyên Quang có thể sử dụng những phương pháp này rèn kỹ năng cho học sinh trong các tiết dạy năng khiếu hát và năng khiếu đàn.

\section{* Đề xuất}

- Đối vói giáo viên

+ Trước khi dạy 1 bài TĐN, giáo viên cần chuẩn bị các phương tiện liên quan đến tiết học như: nhạc cụ̣, bảng phụ và một số câu hỏi về nhạc lý. Trong đó nhạc cụ là phương tiện không thể thiếu trong mỗi bài học, nhằm giúp học sinh phát triển tai nghe qua âm thanh trên đàn.

+ Trong các tiết học, giáo viên cần phải tránh tình trạng "dạy chay" để thu hút sự chú ý của học sinh. Các em sẽ tham gia hoạt động học tập tích cực nếu giáo viên biết cách phối kết hợp các phương tiện và phương pháp dạy học.

+ Không ngừng học tập nâng cao trình độ và học hỏi kinh nghiệm trong quá trình giảng dạy.

- Đối với học sinh

+ Nhiều học sinh chưa nhớ vị trí nốt trên khuông nhạc nên thường viết các ký hiệu $-\mathrm{R}$ - M... (Đô - Rê -Mi...) vào bài TĐN trong sách giáo khoa của mình. Cách làm này khiến học sinh càng lâu thuộc vị trí nốt nhạc, bởi vì khi đọc học sinh chỉ nhìn vào các ký hiệu để đọc mà không nhìn vào nốt nhạc. Để khắc phục tình trạng này, yêu cầu học sinh tuyệt đối không ghi các ký hiệu riêng vào bài TĐN trong sách giáo khoa, khi học bài TĐN trên lớp nên nhìn lên bảng phụ của giáo viên để đọc.

+ Cần ôn lại bài sau giờ học trên lớp.

\section{TÀI LIỆU THAM KHẢO}

[1] Bộ Giáo dục và Đào tạo ((2019), Âm nhạc và Mĩ thuật 6, Nxb Giáo dục Việt Nam.

[2] Bộ Giáo dục và Đào tạo ((2019), Âm nhạc và Mĩ thuật 7, Nxb Giáo dục Việt Nam. 
[3] Bộ Giáo dục và Đào tạo ((2019), Âm nhạc và Mĩ thuật 8, Nxb Giáo dục Việt Nam.

[4] Bộ Giáo dục và Đào tạo ((2019), Âm nhạc và Mĩ thuật 9, Nxb Giáo dục Việt Nam.

[5] Đắc Quỳnh (2003), Xương âm Tập I, Xương âm Tập II, Trường Cao đẳng Sư phạm Nhạc họa TW.

[6] Hoàng Long, Hoàng Lân (2010), Phưong pháp dạy học âm nhạc, Nxb Đại học Sư phạm;
[7] Hoàng Long, Hoàng Lân (2012), Giáo trình Âm nhạc và phuơng pháp dạy học âm nhạc, Nxb Đại học Sư phạm;

[8] Phạm Tú Hương (2004), Giáo trình Lý thuyết âm nhạc co bản, Nxb Đại học Sư phạm Hà Nội;

[9] Trịnh Hoài Thu (2011), Phuoong pháp dạy hoc Ký xướng âm trong đào tạo giáo viên Âm nhạc phổ thông, Nxb Âm nhạc, Hà Nội;

\section{Some methods to practice reading music skill for secondary school students in Tuyen Quang School}

Ha Thi Thuy Linh

\begin{tabular}{l} 
Article info \\
\hline Recieved: \\
24/3/2020 \\
Accepted: \\
10/6/2020
\end{tabular}

Keywords:

reading music; secondary school student; teacher; teaching methods; reading music skill.

\begin{abstract}
In order to achieve the goal and mission of the music at Secondary School, we must create a "certain level of Music Culture", including knowledge, minimun practical competence, and sensory competence about music for students. Therefore, it is imperative that the direct teacher in the classroom has to invest in appropriate time to explore and research in order to find the optimal methods in the process of organizing learning activities for children.

Currently, most secondary school students in Tuyen Quang School (TSE) study the Reading music subject (RMS), they are not good, limited in basic reading music skills. This article gave some methods to train students to practice reading music, such as, high level reading, expressing the length and rhythm; percussion; nuanced reading ... to help the secondary school students in Tuyen Quang school to learn reading music subject more effectively.
\end{abstract}

